\title{
Rate and Determinants of Recurrence at 1 Year and 5 Years After Stroke in a Low-Income Population in Rural China
}

\author{
Jing Han ${ }^{1 \dagger}$, Wenjing $\mathrm{Mao}^{1,2+}$, Jingxian $\mathrm{Ni}^{1,3,4}$, Yanan $\mathrm{Wu}^{1,3,4}$, Jie Liu ${ }^{1,3,4}$, Lingling Bai ${ }^{5}$, \\ Min Shi ${ }^{1,3,4}$, Jun Tu ${ }^{1,3,4}$, Xianjia Ning ${ }^{1,3,4 *}$ and Jinghua Wang ${ }^{1,3,4 *}$ \\ ${ }^{1}$ Department of Neurology, Tianjin Medical University General Hospital, Tianjin, China, ${ }^{2}$ Department of \\ Neurology, The Affiliated Hospital of North China University of Science and Technology, Tangshan, China, ${ }^{3}$ Laboratory of \\ Epidemiology, Tianjin Neurological Institute, Tianjin, China, ${ }^{4}$ Tianjin Neurological Institute, Key Laboratory of Post-Neuroinjury \\ Neuro-repair and Regeneration in Central Nervous System, Ministry of Education and Tianjin City, Tianjin, China, \\ ${ }^{5}$ Department of Neurology, Liaocheng People's Hospital, Liaocheng, China
}

OPEN ACCESS

Edited by:

Ding Ding,

Fudan University, China

Reviewed by:

Shing-Jong Lin,

National Yang-Ming University, Taiwan

Cui Mei,

Fudan University, China

*Correspondence:

Xianjia Ning

xin0906@gmail.com

Jinghua Wang

jhw8799@yahoo.com

tThese authors have contributed equally to this work and share first

authorship

Specialty section:

This article was submitted to

Neuroepidemiology,

a section of the journal

Frontiers in Neurology

Received: 11 December 2018

Accepted: 02 January 2020

Published: 23 January 2020

Citation:

Han J, Mao W, Ni J, Wu Y, Liu J,

Bai L, Shi M, Tu J, Ning $X$ and Wang J

(2020) Rate and Determinants of Recurrence at 1 Year and 5 Years After

Stroke in a Low-Income Population in

Rural China. Front. Neurol. 11:2.

doi: 10.3389/fneur.2020.00002
Recurrent stroke is becoming an increasingly important public health issue owing to the increased risk of disability and death. However, population-based studies investigating the rate of recurrent stroke in China are rare. We explored the rate and determinants of recurrent stroke within 1 and 5 years after the initial stroke in a rural population in China. Data for stroke events were obtained from the Tianjin Brain Study, conducted between 1992 and 2016. The age-standardized rates of recurrent stroke within the first year and the first 5 years after the initial stroke were calculated for this period. Determinants of recurrent stroke were assessed using Cox regression analyses. The overall age-standardized rate of recurrent stroke within 1 year was 5.7\% (men, 6.9\%; women, 4.6\%); within 5 years, the overall recurrent stroke rate was $22.5 \%$ (men, 24.0\%; women, $20.2 \%)$. The recurrence rate increased with advancing age and decreased with increased educational attainment. Age $\geq 65$ years and a history of alcohol consumption were independent risk factors for recurrent stroke within 1 year after the incident stroke, after adjusting for age, sex, education, hypertension, diabetes, smoking, and alcohol consumption. However, the risk of recurrent stroke within 5 years after the incident stroke was positively associated with male sex, age $\geq 65$ years, a lower level of education, known diabetes, and alcohol consumption, after adjusting for the previously indicated covariates. These findings suggest a crucial need to address risk factor management among stroke patients to reduce the burden of stroke, especially among low-income populations. Furthermore, a multicenter, large sample, nationwide study is urgently needed.

Keywords: stroke, recurrence, predictors, epidemiology, incidence

\section{INTRODUCTION}

Stroke is one of the leading causes of death and disability, worldwide (1) and is responsible for $\sim 4.4$ million deaths ( $9 \%$ of total) annually (2). Over the past two decades, there has been a notable increase (84\%) in the absolute numbers of stroke survivors globally although the incidence of stroke has decreased in high-income 
countries (3). However, the number of stroke survivors under 75 years old was almost $30 \%$ higher in low- and middle-income countries than in high-income countries (3). The risk of recurrent stroke is becoming increasingly important owing to its associated high risk of disability and death (4-9), and the risk varies according to the elapsed time since the incident stroke (10-15). The population-based cumulative risk of recurrent stroke during the 5 year period after the incident stroke has been reported to be $19 \%$ in Manhattan (USA), $29 \%$ in Rochester (USA), 30\% in Oxfordshire (UK), and 32\% in Perth (Australia) (16-19).

Each year, there are $\sim 2.5$ million new stroke cases reported in China, and currently there are $\sim 7.5$ million stroke survivors; nationally, the stroke recurrence rate remains high (11.2\%) (20). Over the past few decades, the incidence of stroke has increased in China both in urban and rural populations (21-25). Thus, recurrent stroke prevention is of considerable importance to both individuals and overall public health. However, few populationbased studies have described the incidence of recurrent stroke in China, especially among rural populations. Therefore, in this study, we aimed to assess the rate of recurrent stroke within 1 and 5 years after the incident stroke in rural China.

\section{METHODS}

\section{Study Population}

This study was a population-based stroke surveillance study that began in 1985 in Tianjin, China. The study design has been previously described (23-25). Briefly, it included 15,438 residents living in a township in Tianjin, China, where $95 \%$ of the adults were low-income farmers. The primary source of income was grain production, and the annual per capita income was $<\$ 100$ US in 1990 and <\$2000 USD in 2015 (26). In 1991, the illiteracy rates among residents $35-74$ years old were $30 \%$ for men and $40 \%$ for women. The population characteristics remained stable over the study period (27). Since neuroimaging technology became available in 1992, this study analyzed recurrent stroke events since that time.

The study protocol was approved by the ethics committee of Tianjin Medical University General Hospital (TMUGH); written informed consent was obtained from each participant.

\section{Stroke Definition and Types}

All included stroke events were symptomatic and diagnosed using pre-established criteria, including clinical features and imaging evidence (MRI or CT scan). The initial (incident) stroke was defined as the first occurrence of rapidly developing signs of focal neurologic disturbances of presumed (no other apparent cause) vascular etiology lasting $>24 \mathrm{~h}$ (28). Transient ischemic attacks (TIAs) and silent strokes (diagnosed by imaging only) were excluded, and stroke cases with TIA histories were regarded as incident events. Patients with transient symptoms and concurrent neuroimaging evidence of brain infarctions were considered to be stroke cases, based on the "tissue" definition (29). Recurrent stroke was defined as a new stroke event occurring at least 28 days after the incident event.
The stroke types included ischemic stroke (IS), intracerebral hemorrhage (ICH), and unknown. IS was defined as a thrombotic brain infarction, cardioembolic stroke, or lacunar infarct.

\section{Event Ascertainment Processes}

All incident stroke events included first-ever and recurrent strokes registered according to the previously published procedure (25). Stroke event determinations were performed using a predetermined procedure. First, local village physicians reported stroke events (both initial and recurrent) to the community hospital within $24 \mathrm{~h}$ of onset. Second, community hospital physicians then visited the surviving patients' homes to confirm stroke events and obtain clinical feature information within $72 \mathrm{~h}$. Confirmed stroke events, diagnosed using imaging modalities, were reported each month to neurologists at TMUGH. Suspected events (no imaging performed) were reported in a timely manner. Finally, the TMUGH neurologist identified possible stroke events via door-to-door interviews as soon as possible. To ensure that all incident stroke events were registered, three sources were used to obtain information regarding stroke events. First, local physicians reported events according to a predefined procedure. This was the main information resource, as the local physicians were the first medical professionals to contact the patients. Second, in cases involving inpatient stroke events, the medical records were obtained from the hospital or insurance company. Third, information from the all-cause death registry supplemented stroke events missing from the registry.

Information regarding stroke onset was obtained during interviews conducted by the community hospital physicians and the TMUGH neurologist; information included demographics, time of stroke onset, clinical signs, and previous stroke status. Other information, including imaging characteristics, prescribed therapy, and post-discharge outcomes, was obtained by the TMUGH neurologist during interviews with survivors, their family members, or a local health worker.

The recruitment period was from January 1, 1992, to December 31, 2016, and follow-up was completed on December 31, 2017. During the surveillance period, all stroke events and all-cause deaths were registered and followed. The dates of death or emigration from the township were determined using population registries. All changes in demographic information were recorded, including births, deaths, immigrations (including that due to marriages), and emigrations (including that due to entering a high school or university or working in the city). Peasant workers were included in this study because all residents working in the city were seasonal workers who regularly returned to the township during traditional festivals and the farming season.

\section{Inclusion and Exclusion Criteria}

Only patients who survived the index event were entered into the present analysis. Death was considered to have been caused by the incident stroke if it occurred within 28 days of symptom onset. All patients with at least 1 year of follow-up after their first-ever stroke events were included in this study. Follow-up evaluations were conducted every month, and recurrent strokes 
were classified using information from interviews, conducted directly during follow-up visits or by telephone calls to patients, next of kin, witnesses, or the attending physicians.

All patients with TIAs; suspected stroke deaths without imaging evidence or confirmation by a TMUGH neurologist; and silent strokes, detected only by imaging, were excluded from this study. Patients suffering neuroimaging-confirmed strokes underwent computed tomography or magnetic resonance imaging examinations in the county central hospital.

\section{Statistical Methods}

Categorical variables are presented as numbers (\%), and continuous variables are presented as means (standard deviations, SD). Patient ages were categorized into 3 subgroups ( $<45,45-64$, and $\geq 65$ years) when the demographic features of this population were described and the rates of recurrent stroke were assessed; however, only 2 subgroups ( $<65$ and $\geq 65$ years) were used to assess the determinants of recurrent stroke. Education attainment was categorized into 3 subgroups $(0,1-6$, and $\geq 7$ years). Smoking status was categorized into 3 subgroups (never smoker, past smoker, and current smoker); similarly, drinking status was also categorized into 3 subgroups (never drinkers, past drinkers, and current drinkers). The recurrent stroke incidence was calculated as the cumulative frequency of recurrent events at 1 and 5 years after the incident stroke. Association of education attainment with the risk of the recurrent stroke was assessed by Kaplan-Meier survival analysis and presented as log rank.

Multivariable Cox regression analyses were used to identify the predictors of recurrent stroke within both time periods after adjusted by covariates (sex, age, education attainment, stroke types, previous history of hypertension and diabetes, smoking and drinking status); the risk of recurrent stroke occurrence is presented as adjusted hazard ratios (HRs) and 95\% confidence intervals (CIs). The follow-up time was recorded in years and was calculated as the interval between the date of the initial stroke and the date of the recurrent stroke for those patients experiencing recurrent strokes within 1 and 5 years after the initial stroke. For those patients without recurrent strokes within 1 or 5 years after the initial stroke, the follow-up time was defined as 1 or 5 years, respectively. Moreover, for patients who died within 28 days after the initial stroke, the follow-up time was defined as the interval between the initial stroke and the date of death. During the study period, stroke patients who experienced initial strokes before immigrating to the township were included in the study; stroke patients who emigrated from the township after the initial stroke were excluded from the study. However, in this study, no stroke patients immigrated to or emigrated from the township during the study period. SPSS version 15.0 for Windows (SPSS, Chicago, IL, USA) was used for the analyses; statistical significance was defined as $P<0.05$.

\section{RESULTS}

\section{Patient Characteristics}

A total of 1,185 individuals experienced initial stroke events, including ICH, IS, and undefined events between 1992 and 2016.
All 1,185 patients were included in the determination of the rate and associated predictors of recurrent stroke 1 year after the incident event; patients experiencing incident strokes between January 1, 1992, and December 31, $2012(n=899)$, were included in the determination of the 5 year recurrent stroke rate and its associated predictors.

Between 1992 and 2016, 1,185 initial stroke events were included in this study; the mean time to the first recurrent stroke within the first year was 0.82 years; for the 5 year time frame, the mean time to recurrence was 3.08 years. In both study periods, patients experiencing initial strokes were more likely to be men, older, and less educated. Further, IS was the most common stroke event during these periods (Table 1).

TABLE 1 | Descriptive characteristics of patients with first-ever stroke by time period in this study.

\begin{tabular}{|c|c|c|}
\hline Groups & 1992-2016 & 1992-2012 \\
\hline \multicolumn{3}{|l|}{ SEX, $N(\%):$} \\
\hline Men & $707(59.7)$ & $537(59.7)$ \\
\hline Women & $478(40.3)$ & $362(40.3)$ \\
\hline Total & $1,185(100)$ & $899(100)$ \\
\hline \multicolumn{3}{|c|}{ AGE AT STROKE ONSET, MEAN (SD), YEARS } \\
\hline & $65.49(11.67)$ & $65.54(11.94)$ \\
\hline \multicolumn{3}{|c|}{ AGE GROUPS, $N(\%)$} \\
\hline$<45$ years & $54(4.6)$ & $82(9.1)$ \\
\hline $45-64$ years & $506(42.7)$ & $422(46.9)$ \\
\hline$\geq 65$ years & $625(52.7)$ & $395(43.9)$ \\
\hline \multicolumn{3}{|c|}{ EDUCATION ATTAINMENT, MEAN (SD), YEARS } \\
\hline & $3.35(3.28)$ & $2.89(3.19)$ \\
\hline \multicolumn{3}{|c|}{ EDUCATION GROUPS, $N(\%):$} \\
\hline 0 years & $437(36.9)$ & $390(43.4)$ \\
\hline $1-6$ years & $570(48.1)$ & $407(45.3)$ \\
\hline$\geq 7$ years & $178(15.0)$ & $102(11.3)$ \\
\hline \multicolumn{3}{|c|}{ SUBTYPES OF FIRST-EVER STROKE, $N(\%)$} \\
\hline Ischemic stroke & $916(77.3)$ & $671(74.6)$ \\
\hline $\mathrm{ICH}$ & $231(19.5)$ & $192(21.4)$ \\
\hline UND & $38(3.2)$ & $36(4.0)$ \\
\hline \multicolumn{3}{|c|}{ DIAGNOSIS BY IMAGING FOR FIRST-EVER STROKE, $N(\%):$} \\
\hline Ischemic stroke & 726 (79.3) & $498(74.2)$ \\
\hline $\mathrm{ICH}$ & $218(94.4)$ & $178(92.7)$ \\
\hline Total & $844(71.2)$ & $676(75.2)$ \\
\hline \multicolumn{3}{|c|}{ RECURRENT STROKE EVENTS, $N(\%)$} \\
\hline IS & $45(63.4)$ & $112(55.4)$ \\
\hline $\mathrm{ICH}$ & $12(16.9)$ & $31(15.3)$ \\
\hline Unknown & $14(19.7)$ & $59(29.2)$ \\
\hline Total & $71(100)$ & $202(100)$ \\
\hline \multicolumn{3}{|c|}{ DIAGNOSIS BY IMAGING FOR RECURRENT STROKE, N (\%): } \\
\hline Ischemic stroke & $38(84.4)$ & $97(86.6)$ \\
\hline $\mathrm{ICH}$ & $11(91.7)$ & $22(71.0)$ \\
\hline Unknown & $0(0)$ & $1(1.7)$ \\
\hline Total & $49(69.0)$ & $120(59.4)$ \\
\hline
\end{tabular}

SD indicated standard deviation; 95\% Cl indicates 95\% confidence interval. $\mathrm{ICH}$, Intracerebral hemorrhage; IS, Ischemic stroke; UND, Undefined stroke. 


\section{Recurrent Stroke Rate}

During the study period, 71 recurrent strokes occurred in the 1 year follow-up group and 202 occurred in the 5 year follow-up group. The overall rate of recurrent stroke within 1 year was $5.7 \%$ (men, 6.9\%; women, $4.6 \%$ ); in the 5 year group, the overall rate of recurrent stroke was $22.5 \%$ (men, $24.0 \%$; women, $20.2 \%$ ).

Table 2 shows an increasing rate of recurrent stroke that corresponds with increasing patient age at the time of the initial stroke onset; compared with patients aged $<65$ years old, the rate of recurrent stroke among patients $\geq 65$ years old was higher (7.4\%, $P=0.037)$ in the 1 year follow-up group.

There was no significant association between the rate of recurrent stroke within 1 year and education attainment (log rank $=1.103 ; P=0.576$; Figure 1A). However, there was a negative association between the rate of recurrent stroke within 5 years and education attainment $(\log \operatorname{rank}=8.462 ; P=0.015$; Figure 1B).

TABLE 2 | Age-adjusted rates of recurrent stroke by subtypes [\% (95\% Cl)].

\begin{tabular}{|c|c|c|}
\hline Groups & $\begin{array}{l}\text { Recurrence rate } \\
\text { within } 1 \text { year }\end{array}$ & $\begin{array}{c}\text { Recurrence rate } \\
\text { within } 5 \text { years }\end{array}$ \\
\hline \multicolumn{3}{|l|}{ SEX: } \\
\hline Men & $6.9(5.1,8.8)$ & $24.0(20.4,27.6)$ \\
\hline Women & $4.6(2.7,6.5)$ & $20.2(16.0,24.3)$ \\
\hline Total & $5.7(4.4,6.9)$ & $22.5(19.7,25.2)$ \\
\hline \multicolumn{3}{|c|}{ SUBTYPES OF FIRST-EVER STROKE: } \\
\hline IS & $6.2(4.7,7.8)$ & $24.4(21.2,27.7)$ \\
\hline $\mathrm{ICH}$ & $6.1(3.0,9.2)$ & $19.8(14.1,25.5)$ \\
\hline Other & 0 & 0 \\
\hline \multicolumn{3}{|l|}{ AGE GROUPS: } \\
\hline$<45$ years & 0 & $10.6(1.5,19.8)$ \\
\hline 45-64 years & $4.9(3.0,6.8)$ & $23.8(19.4,28.2)$ \\
\hline$\geq 65$ years & $7.4(5.3,9.4)$ & $22.6(18.9,26.4)$ \\
\hline \multicolumn{3}{|c|}{ EDUCATION: ATTAINMENT: } \\
\hline 0 year & $5.3(3.2,7.4)$ & $18.2(14.4,22.1)$ \\
\hline $1-6$ years & $6.8(4.8,8.9)$ & $28.5(24.1,32.9)$ \\
\hline$\geq 7$ years & $5.1(1.8,8.3)$ & $14.7(7.7,21.7)$ \\
\hline \multicolumn{3}{|c|}{ PREVIOUS DISEASE: HISTORIES: } \\
\hline \multicolumn{3}{|l|}{ Hypertension } \\
\hline Yes & $6.2(4.8,7.7)$ & $22.9(20.0,25.8)$ \\
\hline No & $4.2(0.9,7.5)$ & $19.2(11.3,27.1)$ \\
\hline \multicolumn{3}{|l|}{ Diabetes } \\
\hline Yes & $9.4(4.5,14.3)$ & $39.0(28.2,49.8)$ \\
\hline No & $5.5(4.2,6.9)$ & $20.8(18.0,23.6)$ \\
\hline \multicolumn{3}{|l|}{ LIFESTYLE: } \\
\hline \multicolumn{3}{|l|}{ Smoking status } \\
\hline Never smoked & $5.7(3.9,7.6)$ & $22.3(18.5,26.2)$ \\
\hline Ever smoked & $6.5(1.4,11.7)$ & $30.0(19.0,41.0)$ \\
\hline Current smoking & $6.3(4.1,8.4)$ & $21.2(17.1,25.4)$ \\
\hline \multicolumn{3}{|l|}{ Drinking status } \\
\hline Never drank & $5.7(4.1,7.2)$ & $22.1(18.9,25.4)$ \\
\hline Ever drank & $11.5(4.7,18.3)$ & $43.9(30.6,57.1)$ \\
\hline Current drinker & $5.3(2.7,7.9)$ & $17.9(12.8,23.0)$ \\
\hline
\end{tabular}

\section{Determinants of Stroke Recurrence}

Compared with patients aged $<65$ years old, the risk of stroke recurrence within 1 year after the initial stroke more than doubled among patients $\geq 65$ years $(P=0.004)$ after adjusting for age, sex, education level, hypertension, diabetes, smoking status, and drinking status; there was a lower risk of recurrence for those experiencing an IS than for those with an initial ICH. The risk of recurrent stroke within 5 years after the incident stroke was 1.65 -fold higher among men than among women $(P=0.017)$. Compared with patients aged $<65$ years, the risk of recurrence in patients $\geq 65$ years old increased 1.54 -fold $(P=0.009)$. Similarly, the risk of recurrence in patients with $<7$ years of education was almost double that of patients with at least 7 years of education $(P=0.017)$. The risk was also 1.71 -fold higher among those with a previous diabetes diagnosis than among those without diabetes $(P=0.008)$, and the risk of recurrence was more than two-fold higher among patients who ever drank compared to those who never drank $(P=0.008$; Table 3$)$.

\section{Determinants of Stroke Recurrence Stratified by Age}

Table 3 shows the determinants of recurrent stroke after stratifying the population by age. A history of diabetes was the most common risk factor for recurrent stroke within 1 and 5 years after the initial stroke among patients aged $<65$ years; the recurrence risk increased 2 -fold compared to patients without diabetes. Moreover, the risk of recurrence within 5 years was 1.9fold higher among those with 1-6 years of education compared to those with more than 6 years of education $(P=0.028)$.

Among patients aged $\geq 65$ years, the risk of recurrence within the first post-stroke year was $57 \%$ lower in patients experiencing initial IS than in those experiencing initial ICH $(P=0.033)$; this patient group also had a $79 \%$ lower risk of recurrent stroke among those who ever smoked than among those who had never smoked $(P=0.046)$. However, there was a 3.6-fold higher risk of recurrence for those who ever drank than among those who never drank $(P=0.025)$. The risk of recurrence within 5 years increased $>2$-fold among patients who ever drank compared to that among those who never $\operatorname{drank}(P=0.021)$.

\section{DISCUSSION}

This is the first population-based report evaluating the recurrent stroke rate in rural China. In this study, we assessed the rate of recurrent stroke within $1(5.7 \%)$ and $5(22.5 \%)$ years after the first-ever stroke. The recurrence rate over both time periods increased significantly with advancing age. After adjusting for age, sex, education level, hypertension, diabetes, smoking, and alcohol consumption, advanced age was an independent predictor of recurrent stroke within both time frames among the overall population. Moreover, male patients, patients with lower educational attainment, and those with a known diabetes history had higher risks of recurrent stroke within the 5 year period. Further, age-stratified analysis showed that known diabetes history was an independent risk factor of stroke recurrence at both 1 and 5 years after the initial stroke among stroke patients 

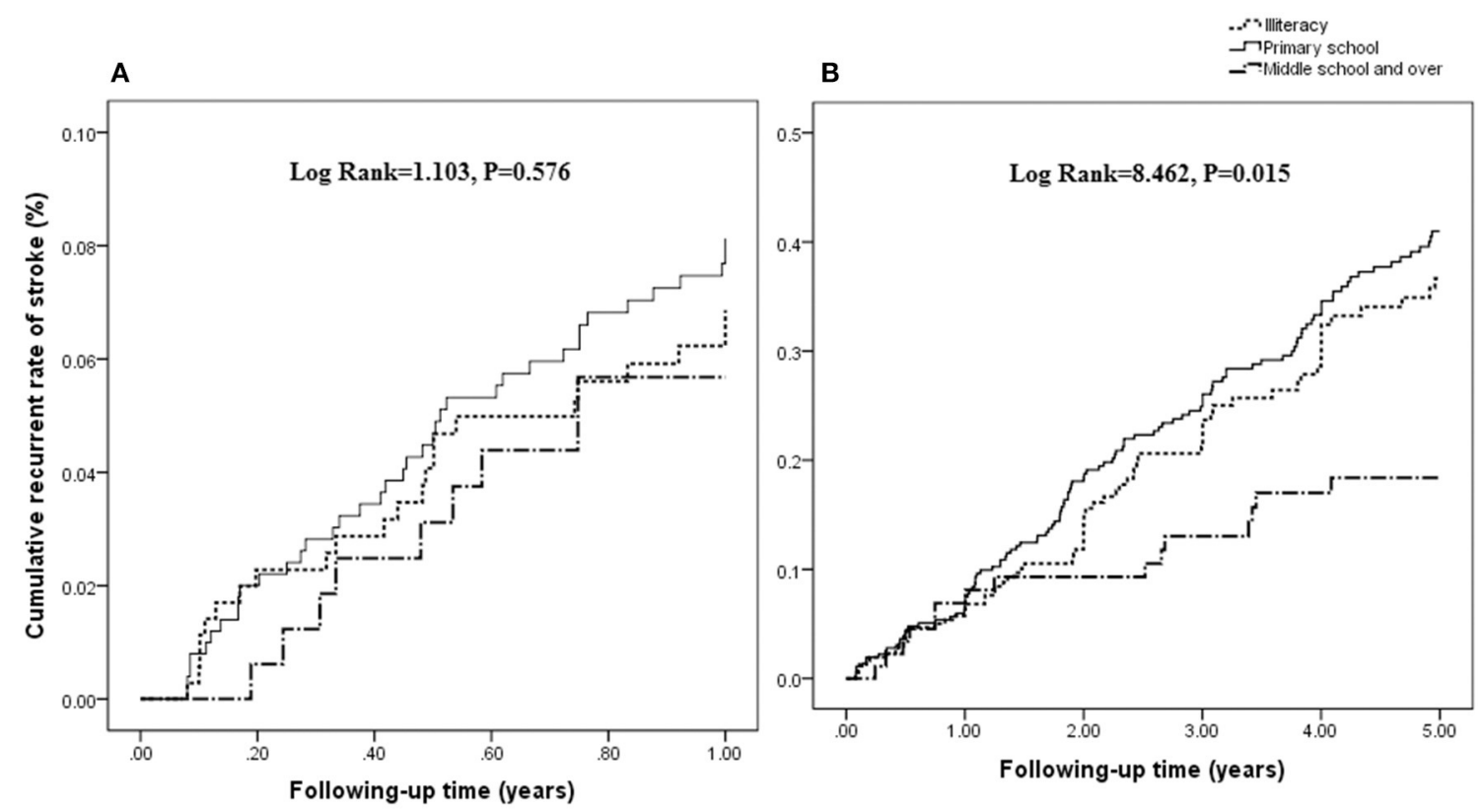

FIGURE 1 | Association between the rate of recurrent stroke and education attainment. There was no significant association between the rate of recurrent stroke within 1 year and education attainment (log rank $=1.103 ; P=0.576$; $\mathbf{A})$. However, a negative association is shown between the rate of recurrent stroke within 5 years and education attainment $(\log r a n k=8.462 ; P=0.015 ; \mathbf{B})$.

aged $<65$ years old. Moreover, patients with a lower educational attainment (1-6 years) had a high risk of stroke recurrence. However, for patients aged 65 years and over, ever drinking was an independent risk factor of recurrent stroke at both 1 and 5 years after initial stroke onset. In addition, experiencing initial IS and ever smoking were independent protective factors for risk of stroke recurrence among elderly individuals.

The stroke recurrence rate remains controversial. The risk of stroke recurrence is reported to range from 7.0 to $20.6 \%$ over the first year $(4,12,13)$, from 16.2 to $35.3 \%$ over the first 5 years $(4,10,14)$, and from 14 to $51.3 \%$ over the first 10 years after the initial stroke $(4,10,15)$. A population-based cohort study from the Middle East indicated that the cumulative incidence of stroke recurrence was $14.5 \%$ by the end of 5 years, with the highest rate occurring during the 1st year after the initial stroke (5.6\%) (29). In the present study, the 1 and 5 year recurrence rates were 5.7 and $22.5 \%$, which are within the range reported previously. This finding suggests that more than $20 \%$ of patients will suffer a recurrent stroke within the first 5 years. The relatively low recurrence rates observed in this study are most likely due to the relatively young (average age $<65$ years) study population.

The disparity among the reported recurrence rates may be partially explained by the differing definitions of stroke recurrence. There is wide variation in the definition of recurrent stroke, ranging from any focal neurological deficit lasting $>24 \mathrm{~h}$ and occurring after an initial stroke $(14,16,18,30)$ to an event occurring $>28$ days after an initial stroke $(31,32)$. In the present study, recurrent stroke was defined as a stroke occurring $>28$ days after the incident stroke.
In the present study, age was identified as a predictor of recurrent stroke. A previous study from northern Sweden indicated that the risk of stroke recurrence rose by $3 \%$ for every additional year of age (8). A similar trend was reported in a study from the Middle East where a $2 \%$ increase in risk was observed for every additional year of age (29). Another study suggested that the risk of recurrence significantly increased among patients $>75$ years old compared to patients $<65$ years old; the risk of recurrence increased by $13 \%$ in patients $76-85$ years old and by $16 \%$ in those $>85$ years old (33). In the present study, relative to patients who were $<65$ years old, we observed a $129 \%$ and a $54 \%$ increase in the 1 and 5 year risks, respectively, of recurrent stroke among patients $\geq 65$ years old.

Reports of sex-based differences in stroke outcomes are also inconsistent. Several previous studies have reported worse outcomes among women than among men, with women demonstrating greater functional impairment, mortality, recurrence, and dependency rates 3 and 12 months post-stroke $(1,34,35)$. However, other studies have not reported these sexbased differences (36). In the present study, there was a higher risk of recurrence among men than among women within the 5 year period after the incident stroke, but this difference was not evident within the first year. In this population, the young age of stroke onset and the poor management of post-stroke risk factors among men may have contributed to the observed sex-based differences in recurrence.

There is strong evidence for an inverse relationship between socioeconomic status (SES) and stroke incidence and mortality (37-39). However, evidence for a potential association between SES and stroke recurrence is limited (39). Previous studies 
TABLE 3 | Determinants of recurrent stroke at 1 and 5 years after the first-ever stroke among the study population (HR with 95\% Cl).

\begin{tabular}{|c|c|c|c|c|c|c|c|}
\hline \multirow[t]{2}{*}{ Predictors } & \multirow[t]{2}{*}{ Reference } & \multicolumn{2}{|c|}{ Overall } & \multicolumn{2}{|c|}{$<65$ years } & \multicolumn{2}{|c|}{$\geq 65$ years } \\
\hline & & Within 1 year & Within 5 years & Within 1 year & Within 5 years & Within 1 year & Within 5 years \\
\hline Sex: & Women & & & & & & \\
\hline Men & & $1.67(0.85,3.26)$ & $1.65(1.09,2.50)^{\star}$ & $1.75(0.47,6.44)$ & $1.79(0.82,3.89)$ & $1.59(0.72,3.47)$ & $1.55(0.94,2.55)$ \\
\hline Age groups: & $<65$ years & & & & & & \\
\hline$\geq 65$ years & & $2.29(1.31,4.00)^{\star}$ & $1.54(1.11,2.12)^{\star}$ & - & - & - & - \\
\hline Education attainment: & $\geq 7$ years & & & & & & \\
\hline 0 year & & $0.88(0.37,2.11)$ & $1.55(0.83,2.87)$ & $0.36(0.04,3.03)$ & $0.91(0.37,2.23)$ & $2.29(0.30,17.37)$ & - \\
\hline $1-6$ years & & $1.21(0.57,2.58)$ & $1.96(1.13,3.42)^{\star}$ & $1.10(0.46,2.62)$ & $1.90(1.07,3.38)^{\star}$ & $2.96(0.40,22.16)$ & - \\
\hline First-ever stroke types: & $\mathrm{ICH}$ & & & & & & \\
\hline IS & & $0.53(0.29,0.96)^{\star}$ & $0.70(0.48,1.01)$ & $0.63(0.24,1.64)$ & $0.63(0.39,1.03)$ & $0.43(0.20,0.94)^{\star}$ & $0.73(0.41,1.29)$ \\
\hline Hypertension: & No & & & & & & \\
\hline Yes & & $1.39(0.59,3.26)$ & $0.98(0.60,1.60)$ & $1.16(0.27,5.01)$ & $0.89(0.38,2.09)$ & $1.65(0.57,4.74)$ & $1.17(0.64,2.12)$ \\
\hline Diabetes: & No & & & & & & \\
\hline Yes & & $1.73(0.93,3.22)$ & $1.71(1.15,2.54)^{\star}$ & $3.19(1.30,7.79)^{\star}$ & $2.95(1.75,4.96)^{\star}$ & $1.11(0.43,2.88)$ & $0.88(0.45,1.73)$ \\
\hline Smoking status: & Never & & & & & & \\
\hline Past smoker & & $0.36(0.11,1.15)$ & $0.52(0.27,1.00)$ & $0.76(0.11,5.35)$ & $0.63(0.23,1.78)$ & $0.21(0.05,0.98)^{\star}$ & $0.43(0.16,1.14)$ \\
\hline Current smoker & & $0.84(0.43,1.65)$ & $0.70(0.46,1.06)$ & $0.59(0.13,2.70)$ & $0.73(0.32,1.63)$ & $0.95(0.45,2.01)$ & $0.70(0.42,1.15)$ \\
\hline Drinking status: & Never & & & & & & \\
\hline Past drinkers & & $2.46(0.99,6.11)$ & $2.23(1.24,4.01)^{\star}$ & $1.82(0.35,9.42)$ & $1.74(0.77,3.92)$ & $3.60(1.18,11.01)^{*}$ & $3.09(1.19,8.05)^{\star}$ \\
\hline Current drinkers & & $0.90(0.44,1.84)$ & $0.86(0.56,1.32)$ & $1.41(0.36,5.53)$ & $0.92(0.48,1.79)$ & $0.70(0.28,1.75)$ & $0.73(0.39,1.37)$ \\
\hline
\end{tabular}

${ }^{\star} P<0.05$ compared to reference.

suggested that this relationship was sex-based $(40,41)$, but no significant association between SES and stroke recurrence was found in another population-based-study (10). In the present study, a higher risk of recurrent stroke within 5 years after the incident stroke was observed in patients with lower levels of education (1-6 years) than in those with higher levels of education ( $\geq 7$ years) in the overall population and in those aged $<65$ years old. However, the risk of recurrent stroke within 5 years after the incident stroke was not higher in those without education attainment (illiteracy) in the overall population and among those aged $<65$ years old; the lower number of patients with higher levels of education ( $\geq 7$ years) in the overall population $(11.3 \%)$ and the lower number of patients with lower levels of education among those aged $<65$ years old (15\%) may partly explain this disparity. Furthermore, the higher percentage of female patients in the illiterate group may contribute to the association of lower education levels with poor stroke outcomes. Poor risk factor management and limited access to medicine among those with lower educational attainment and income may partially explain this relationship $(42,43)$.

The association between smoking and stroke risk remains controversial. In the Framingham Heart Study, smoking cessation was associated with a significantly lower risk of cardiovascular disease within 5 years among heavy smokers relative to current smokers; however, relative to never smokers, former smokers' cardiovascular disease risk remained significantly elevated beyond 5 years after smoking cessation (44). Another study from the Intracerebral Hemorrhage Outcomes Project found that the functional outcomes among patients with intracerebral hemorrhage were similar between recent smokers and former smokers (45). In the present study, a lower risk of recurrent stroke was found in patients who had ever smoked in the overall population and among elderly stroke patients within 1 year after their initial stroke. The neuroprotective effect of nicotine might explain this finding partly (46-48). The exact cause however needs further research.

Heavy alcohol consumption is well-known risk factor for stroke $(49,50)$, but the relationship between the risk of recurrent stroke and alcohol consumption remains unknown, especially in China. Alcohol consumption independently predicted impairment 2 years after stroke in one study (51), but no association with functional outcomes after stroke was found in other studies (52-54). In this study, ever drinking was an independent risk factor for recurrence in the overall population and among elderly stroke patients at both 1 and 5 years after the initial stroke. In this population, patients drank in the past ceased drinking alcohol after developing severe diseases; this may explain the positive association between ever drinking and stroke recurrence.

Several studies have suggested that diabetes mellitus is an important predictor of recurrent stroke (55-57). Consistent with these studies, in the present study, we observed a significant association between diabetes mellitus and stroke recurrence for the whole study population and those patients aged $<65$ years.

This study has several limitations. First, the study population was from a township in northern China, which is not representative of the overall population of China. However, the prospective study design and long study period may have decreased recall and selection bias. Moreover, the 362,596 person-years of total follow-up fulfill the 100,000 person-years 
of follow-up criterion for population studies (58). Second, we did not collect detailed information regarding dietary habits and medication use; therefore, other possible determinants of stroke recurrence could not be assessed in this study. Third, data on smoking and alcohol consumption were not available in this study; this may affect the specific evaluation of the relationship between smoking or alcohol consumption and stroke recurrence. Fourth, our study lacks data on medication usage. However, in this low-income population, the rate of using medicine was lower; thus, the impact of medication usage on stroke recurrence may be ignored. Finally, information regarding medical care among these stroke patients was not available. This was a low-income, poorly educated population, and few had medical insurance before 2008. Thus, they would have been taken care of by family members, including spouses, children, siblings, and others. Only unmarried men who suffered strokes were sent to the official nursing home.

\section{CONCLUSIONS}

This report assessed the rate of recurrent stroke in rural China using a population-based study design. The rates of recurrent stroke within 1 and 5 years after the first-ever stroke were 5.7 and $22.5 \%$ and increased significantly with advancing age. The determinants of stroke recurrence were associated with age. After adjusting for covariates, a known diabetes history was an independent risk factor for stroke recurrence at both 1 and 5 years after the initial stroke among patients aged $<65$ years old; moreover, lower educational attainment (1-6 years) increased the risk of stroke recurrence. However, for patients aged 65 years and over, ever drinking was an independent risk factor for recurrent stroke at both 1 and 5 years after the initial stroke

\section{REFERENCES}

1. Wang Z, Li J, Wang C, Yao X, Zhao X, Wang Y, et al. Gender differences in 1 year clinical characteristics and outcomes after stroke: results from the China National Stroke Registry. PLoS ONE. (2013) 8:e56459. doi: 10.1371/journal.pone.0056459

2. Kissela BM, Khoury JC, Alwell K, Moomaw CJ, Woo D, Adeoye O, et al. Age at stroke: temporal trends in stroke incidence in a large, biracial population. Neurology. (2012) 79:1781-7. doi: 10.1212/WNL.0b013e318270401d

3. Feigin VL, Forouzanfar MH, Krishnamurthi R, Mensah GA, Connor M, Bennett DA, et al. Global and regional burden of stroke during 1990-2010: findings from the Global Burden of Disease Study 2010. Lancet. (2014) 383:245-54. doi: 10.1016/S0140-6736(13)61953-4

4. Mohan KM, Wolfe CD, Rudd AG, Heuschmann PU, KolominskyRabas PL, Grieve AP. Risk and cumulative risk of stroke recurrence: a systematic review and meta-analysis. Stroke. (2011) 42:1489-94. doi: 10.1161/STROKEAHA.110.602615

5. Appelros P, Jonsson F, Åsberg S, Asplund K, Glader EL, Åsberg KH, et al. Trends in stroke treatment and outcome between 1995 and 2010: observations from Riks-Stroke, the Swedish stroke register. Cerebrovasc Dis. (2014) 37:229. doi: 10.1159/000356346

6. Kang K, Park TH, Kim N, Jang MU, Park SS, Park JM, et al. Recurrent stroke, myocardial infarction, and major vascular events during the first year after acute ischemic stroke: the multicenter prospective observational study about recurrence and its determinants after acute ischemic stroke I. J Stroke onset; experiencing an initial IS and ever smoking were protective factors for the risk of stroke recurrence. These findings suggest a crucial need to address risk factor management among stroke patients to reduce the burden of stroke, especially among lowincome populations. Furthermore, a multicenter, large sample, nationwide study is urgently needed.

\section{DATA AVAILABILITY STATEMENT}

All datasets generated for this study are included in the artical/supplementary material.

\section{ETHICS STATEMENT}

The study protocol was approved by the ethics committee of Tianjin Medical University General Hospital (TMUGH); written informed consent was obtained from each participant.

\section{AUTHOR CONTRIBUTIONS}

JW and XN contributed to the study design, performed data collection, data interpretation, and critical review. JW performed data analysis. JH and WM contributed to drafting of the article. JH, WM, JN, YW, JL, LB, MS, and JT performed data collection, case diagnoses, and confirmation of case diagnoses. All authors read, revised, and approved the final version of the paper.

\section{ACKNOWLEDGMENTS}

We thank all participants of the Tianjin Brain Study, and local medical care professionals for their valuable contributions.

Cerebrovasc Dis. (2016) 25:656-64. doi: 10.1016/j.jstrokecerebrovasdis.2015. 11.036

7. Callaly E, Ni Chroinin D, Hannon N, Marnane M, Akijian L, Sheehan O, et al. Rates, predictors, and outcomes of early and late recurrence after stroke: the North Dublin Population Stroke Study. Stroke. (2016) 47:2446. doi: 10.1161/STROKEAHA.115.011248

8. Pennlert J, Eriksson M, Carlberg B, Wiklund PG. Long-term risk and predictors of recurrent stroke beyond the acute phase. Stroke. (2014) 45:183941. doi: 10.1161/STROKEAHA.114.005060

9. Lee S, Shafe AC, Cowie MR. UK stroke incidence, mortality and cardiovascular risk management 1999-2008: timetrend analysis from the General Practice Research Database. BMJ Open. (2011) 1:e000269. doi: 10.1136/bmjopen-2011000269

10. Mohan KM, Crichton SL, Grieve AP, Rudd AG, Wolfe CD, Heuschmann PU. Frequency and predictors for the risk of stroke recurrence up to 10 years after stroke: the South London stroke register. J Neurol Neurosurg Psych. (2009) 80:1012-8. doi: 10.1136/jnnp.2008.170456

11. Coull AJ, Lovett JK, Rothwell PM, Oxford Vascular Study. Population based study of early risk of stroke after transient ischaemic attack or minor stroke: implications for public education and organisation of services. BMJ. (2004) 328:326-8. doi: 10.1136/bmj.37991.635266.44

12. Salgado AV, Ferro JM, Gouveia-Oliveira A. Long-term prognosis of firstever lacunar strokes. A hospital-based study. Stroke. (1996) 27:6616. doi: 10.1161/01.STR.27.4.661 
13. Xu G, Liu X, Wu W, Zhang R, Yin Q. Recurrence after ischemic stroke in chinese patients: impact of uncontrolled modifiable risk factors. Cerebrovasc Dis. (2007) 23:117-20. doi: 10.1159/000097047

14. Hata J, Tanizaki Y, Kiyohara Y, Kato I, Kubo M, Tanaka K, et al. Ten year recurrence after first ever stroke in a Japanese community: the Hisayama study. J Neurol Neurosurg Psych. (2005) 76:368-72. doi: 10.1136/jnnp.2004.038166

15. Prencipe M, Culasso F, Rasura M, Anzini A, Beccia M, Cao M, et al. Long-term prognosis after a minor stroke: 10 year mortality and major stroke recurrence rates in a hospital-based cohort. Stroke. (1998) 29:12632. doi: 10.1161/01.STR.29.1.126

16. Dhamoon MS, Sciacca RR, Rundek T, Sacco RL, Elkind MS. Recurrent stroke and cardiac risks after first ischemic stroke: the Northern Manhattan Study. Neurology. (2006) 66:641-6. doi: 10.1212/01.wnl.0000201253.93811.f6

17. Hardie K, Jamrozik K, Hankey GJ, Broadhurst RJ, Anderson C. Trends in 5 year survival and risk of recurrent stroke after first-ever stroke in the Perth Community Stroke Study. Cerebrovasc Dis. (2005) 19:17985. doi: $10.1159 / 000083253$

18. Petty GW, Brown J, Whisnant JP, Sicks JD, O’Fallon WM, Wiebers DO. Survival and recurrence after first cerebral infarction: a population-based study in Rochester, Minnesota, 1975 through 1989. Neurology. (1998) 50:20816. doi: 10.1212/WNL.50.1.208

19. Burn J, Dennis M, Bamford J, Sandercock P, Wade D, Warlow C. Long-term risk of recurrent stroke after a first-ever stroke. The Oxfordshire Community Stroke Project. Stroke. (1994) 25:333-7. doi: 10.1161/01.STR.25.2.333

20. Liu L, Wang D, Wong KS, Wang Y. Stroke and stroke care in China: huge burden, significant workload, and a national priority. Stroke. (2011) 42:3651-4. doi: 10.1161/STROKEAHA.111.635755

21. Zhao D, Liu J, Wang W, Zeng Z, Cheng J, Liu J, et al. Epidemiological transition of stroke in China: twenty-one-year observational study from the Sino-MONICA-Beijing Project. Stroke. (2008) 39:1668-74. doi: 10.1161/STROKEAHA.107.502807

22. Jiang B, Wang WZ, Chen H, Hong Z, Yang QD, Wu SP, et al. Incidence and trends of stroke and its subtypes in China: results from three large cities. Stroke. (2006) 37:63-8. doi: 10.1161/01.STR.0000194955.34820.78

23. Ning X, Sun J, Jiang R, Lu H, Bai L, Shi M, et al. Increased stroke burdens among the low-income young and middle aged in rural China. Stroke. (2017) 48:77-83. doi: 10.1161/STROKEAHA.116.014897

24. Wang J, Bai L, Shi M, Yang L, An Z, Li B, et al. Trends in age of first-ever stroke following increased incidence and life expectancy in a low-income Chinese population. Stroke. (2016) 47:929-35. doi: 10.1161/STROKEAHA.115.012466

25. Wang J, An Z, Li B, Yang L, Tu J, Gu H, et al. Increasing stroke incidence and prevalence of risk factors in a low-income Chinese population. Neurology. (2015) 84:374-81. doi: 10.1212/WNL.0000000000001175

26. National Bureau of Statistics of China. In China Statistical Yearbook-2016. Beijing: China Statistics Press (2016).

27. Wang J, Ning $\mathrm{X}$, Yang $\mathrm{L}, \mathrm{Lu} \mathrm{H}, \mathrm{Tu} \mathrm{J}$, Jin $\mathrm{W}$, et al. Trends of hypertension prevalence, awareness, treatment and control in rural areas of northern China during 1991-2011. J Hum Hypertens. (2014) 28:2531. doi: $10.1038 /$ jhh. 2013.44

28. Aho K, Harmsen P, Hatano S, Marquardsen J, Smirnov VE, Strasser T. Cerebrovascular disease in the community: results of a WHO collaborative study. Bull World Health Organ. (1980) 58:113-30.

29. Salehi M, Amiri A, Thrift AG, Kapral MK, Sposato L, Behrouz R, et al. Fiveyear recurrence rate and the predictors following stroke in the mashhad stroke incidence study: a population-based Cohort study of stroke in the Middle East. Neuroepidemiology. (2018) 50:18-22. doi: 10.1159/000485509

30. Modrego PJ, Mainar R, Turull L. Recurrence and survival after first-ever stroke in the area of Bajo Aragon, Spain. A prospective cohort study. J Neurol Sci. (2004) 224:49-55. doi: 10.1016/j.jns.2004.06.002

31. Elneihoum AM, Goransson M, Falke P, Janzon L. Three-year survival and recurrence after stroke in Malmo, Sweden: an analysis of stroke registry data. Stroke. (1998) 29:2114-7. doi: 10.1161/01.STR.29.10.2114

32. Azarpazhooh MR, Nicol MB, Donnan GA, Dewey HM, Sturm JW, Macdonell RA, et al. Patterns of stroke recurrence according to subtype of first stroke event: the North East Melbourne Stroke Incidence Study (NEMESIS). Int J Stroke. (2008) 3:158-64. doi: 10.1111/j.1747-4949.2008. 00204.x
33. Bergström L, Irewall AL, Söderström L, Ögren J, Laurell K, Mooe T. Oneyear incidence, time trends, and predictors of recurrent ischemic stroke in sweden from 1998 to 2010: an observational study. Stroke. (2017) 48:204651. doi: 10.1161/STROKEAHA.117.016815

34. Gall SL, Donnan G, Dewey HM, Macdonell R, Sturm J, Gilligan $A$, et al. Sex differences in presentation, severity, and management of stroke in a population-based study. Neurology. (2010) 74:975-81. doi: 10.1212/WNL.0b013e3181d5a48f

35. Knauft W, Chhabra J, McCullough LD. Emergency department arrival times, treatment, and functional recovery in women with acute ischemic stroke. $J$ Womens Health. (2010) 19:681-8. doi: 10.1089/jwh.2009.1616

36. Jönsson AC, Ek J, Kremer C. Outcome of men and women after atrial fibrillation and stroke. Acta Neurol Scand. (2015) 132:125-31. doi: 10.1111/ane.12366

37. Kerr GD, Slavin H, Clark D, Coupar F, Langhorne P, Stott DJ. Do vascular risk factors explain the association between socioeconomic status and stroke incidence: a meta-analysis. Cerebrovasc Dis. (2011) 31:5763. doi: $10.1159 / 000320855$

38. Cox AM, McKevitt C, Rudd AG, Wolfe CD. Socioeconomic status and stroke. Lancet Neurol. (2006) 5:181-8. doi: 10.1016/S1474-4422(06)70351-9

39. Marshall IJ, Wang Y, Crichton S, McKevitt C, Rudd AG, Wolfe CD. The effects of socioeconomic status on stroke risk and outcomes. Lancet Neurol. (2015) 14:1206-18. doi: 10.1016/S1474-4422(15)00200-8

40. Li C, Hedblad B, Rosvall M, Buchwald F, Khan FA, Engström G. Stroke incidence, recurrence, and case-fatality in relation to socioeconomic position: a population-based study of middle-aged Swedish men and women. Stroke. (2008) 39:2191-6. doi: 10.1161/STROKEAHA.107.507756

41. Cesaroni G, Agabiti N, Forastiere F, Perucci CA. Socioeconomic differences in stroke incidence and prognosis under a universal healthcare system. Stroke. (2009) 40:2812-9. doi: 10.1161/STROKEAHA.108.542944

42. Sjöander M, Eriksson M, Glader EL. Social stratification in the dissemination of statins after stroke in Sweden. Eur J Clin Pharmacol. (2013) 69:117380. doi: $10.1007 / \mathrm{s} 00228-012-1454-8$

43. Sjöander M, Eriksson M, Asplund K, Norrving B, Glader EL. Socioeconomic inequalities in the prescription of oral anticoagulants in stroke patients with atrial fibrillation. Stroke. (2015) 46:22205. doi: 10.1161/STROKEAHA.115.009718

44. Duncan MS, Freiberg MS, Greevy RA Jr, Kundu S, Vasan RS, Tindle HA. Association of smoking cessation with subsequent risk of cardiovascular disease. JAMA. (2019) 322:642-50. doi: 10.1001/jama.2019.10298

45. Ironside N, Chen CJ, Pucci J, Connolly ES. Effect of cigarette smoking on functional outcomes in patients with spontaneous intracerebral hemorrhage. J Stroke Cerebrovasc Dis. (2019) 28:2496-505. doi: 10.1016/j.jstrokecerebrovasdis.2019.06.013

46. Neumann S, Shields NJ, Balle T, Chebib M, Clarkson AN. Innate immunity and inflammation post-stroke: an alpha7-nicotinic agonist perspective. Int $J$ Mol Sci. (2015) 16:29029-46. doi: 10.3390/ijms161226141

47. Hijioka M, Matsushita H, Ishibashi H, Hisatsune A, Isohama Y, Katsuki H. Alpha7 nicotinic acetylcholine receptor agonist attenuates neuropathological changes associated with intracerebral hemorrhage in mice. Neuroscience. (2012) 222:10-9. doi: 10.1016/j.neuroscience.2012.07.024

48. Hijioka M, Matsushita H, Hisatsune A, Isohama Y, Katsuki H. Therapeutic effect of nicotine in a mouse model of intracerebral hemorrhage. J Pharmacol Exp Ther. (2011) 338:741-9. doi: 10.1124/jpet.111.182519

49. Patra J, Taylor B, Irving H, Roerecke M, Baliunas D, Mohapatra S, et al. Alcohol consumption and the risk of morbidity and mortality for different stroke types-a systematic review and meta-analysis. BMC Public Health. (2010) 10:258. doi: 10.1186/1471-2458-10-258

50. O’Donnell MJ, Xavier D, Liu L, Zhang H, Chin SL, Rao-Melacini P, et al. Risk factors for ischaemic and intracerebral haemorrhagic stroke in 22 countries [the INTERSTROKE study]: a case-control study. Lancet. (2010) 376:11223. doi: 10.1016/S0140-6736(10)60834-3

51. Aarnio K, Haapaniemi E, Melkas S, Kaste M, Tatlisumak T, Putaala J. Long-term mortality after first-ever and recurrent stroke in young adults. Stroke. (2014) 45:2670-6. doi: 10.1161/STROKEAHA.114.0 05648

52. Fekete K, Szatmári S, Szocs I, Szekeres C, Szász J, Mihálka L, et al. Prestroke alcohol consumption and smoking are not associated with stroke severity, 
disability at discharge, and case fatality. J Stroke Cerebrovasc Dis. (2014) 23:e31-7 doi: 10.1016/j.jstrokecerebrovasdis.2013.08.006

53. Mukamal KJ, Chung H, Jenny NS, Kuller LH, Longstreth WT Jr, Mittleman MA, et al. Alcohol use and risk of ischemic stroke among older adults: the Cardiovascular Health Study. Stroke. (2005) 36:18304. doi: 10.1161/01.STR.0000177587.76846.89

54. Jørgensen HS, Reith J, Nakayama H, Kammersgaard LP, Raaschou HO, Olsen TS. What determines good recovery in patients with the most severe strokes? The Copenhagen Stroke Study. Stroke. (1999) 30:200812. doi: 10.1161/01.STR.30.10.2008

55. Kissela BM, Khoury J, Kleindorfer D, Woo D, Schneider A, Alwell K, et al. Epidemiology of ischemic stroke in patients with diabetes: the greater Cincinnati/Northern Kentucky Stroke Study. Diabetes Care. (2005) 28:3559. doi: $10.2337 /$ diacare.28.2.355

56. Kamalesh M, Shen J, Eckert GJ. Long term post ischemic stroke mortality in diabetes: a veteran Cohort analysis. Stroke. (2008) 39:272731. doi: 10.1161/STROKEAHA.108.517441

57. Callahan A, Amarenco P, Goldstein LB, Sillesen H, Messig M, Samsa GP, et al. Risk of stroke and cardiovascular events after ischemic stroke or transient ischemic attack in patients with type 2 diabetes or metabolic syndrome: secondary analysis of the Stroke Prevention by Aggressive Reduction in Cholesterol Levels (SPARCL) trial. Arch Neurol. (2011) 68:124551. doi: 10.1001/archneurol.2011.146

58. Coull AJ, Silver LE, Bull LM, Giles MF, Rothwell PM; Oxford Vascular (OXVASC) Study. Direct assessment of completeness of ascertainment in a stroke incidence study. Stroke. (2004) 35:2041-5. doi: 10.1161/01.STR.0000137605.48 $864.2 \mathrm{f}$

Conflict of Interest: The authors declare that the research was conducted in the absence of any commercial or financial relationships that could be construed as a potential conflict of interest.

Copyright $\odot 2020$ Han, Mao, Ni, Wu, Liu, Bai, Shi, Tu, Ning and Wang. This is an open-access article distributed under the terms of the Creative Commons Attribution License (CC BY). The use, distribution or reproduction in other forums is permitted, provided the original author(s) and the copyright owner(s) are credited and that the original publication in this journal is cited, in accordance with accepted academic practice. No use, distribution or reproduction is permitted which does not comply with these terms. 